\section{Case Reports in Ophthalmology}

Case Rep Ophthalmol 2017;8:406-409

DOI: $10.1159 / 000478924$

Published onlıne: July 26, 2017
(C) 2017 The Author(s)

Published by S. Karger AG, Basel www.karger.com/cop

This article is licensed under the Creative Commons Attribution-NonCommercial 4.0 International License (CC BY-NC) (http://www.karger.com/Services/OpenAccessLicense). Usage and distribution for commercial purposes requires written permission.

\title{
Fundus Findings in Wernicke Encephalopathy
}

\author{
Tal Serlin Elad Moisseiev \\ Department of Ophthalmology, Tel Aviv Medical Center, Tel Aviv, Israel
}

\section{Keywords}

Wernicke encephalopathy $\cdot$ Bariatric surgery $\cdot$ Sleeve gastrectomy $\cdot$ Optic disc edema $\cdot$ Retinal hemorrhage · Fundus

\begin{abstract}
Wernicke encephalopathy (WE) is an acute neuropsychiatric syndrome resulting from thiamine (vitamin $B_{1}$ ) deficiency, classically characterized by the triad of ophthalmoplegia, confusion, and ataxia. While commonly associated with chronic alcoholism, WE may also occur in the setting of poor nutrition or absorption. We present a 37-year-old woman who underwent laparoscopic sleeve gastrectomy and presented with visual disturbance with bilateral horizontal nystagmus, confusion, and postural imbalance. Fundus examination revealed bilateral optic disc edema with a retinal hemorrhage in the left eye. Metabolic workup demonstrated thiamine deficiency. Her symptoms resolved after thiamine treatment. This case raises the awareness of the possibility of posterior segment findings in $\mathrm{WE}$, which are underreported in WE.

(C) 2017 The Author(s) Published by S. Karger AG, Basel
\end{abstract}

\section{Introduction}

Thiamine (vitamin $\mathrm{B}_{1}$ ) is a water-soluble essential nutrient with a limited intracellular reserve that requires constant supplementation [1]. Dietary thiamine deficiency may manifest in 2 clinical phenotypes: Wernicke-Korsakoff syndrome and beriberi. The term Wer- 
nicke-Korsakoff syndrome encompasses 2 different clinical entities: Korsakoff syndrome is a chronic neurologic condition, defined as a disproportionate impairment in memory relative to other aspects of cognitive function, occurring as a late complication of Wernicke encephalopathy (WE).

WE is an acute neuropsychiatric syndrome characterized by nystagmus and ophthalmoplegia, mental status changes, and unsteadiness of posture and gait. While laboratory analysis is useful for confirmation of vitamin $\mathrm{B}_{1}$ deficiency, WE is a clinical diagnosis that requires a prompt initiation of parenteral thiamine replacement under clinical monitoring [2].

WE may result following all types of bariatric surgical procedures [3]. However, development of WE after restrictive procedures, such as laparoscopic sleeve gastrectomy (LSG), is uncommon, and only 16 documented cases were reported in the literature. Persistent vomiting was suggested as the most important precipitating factor in these patients [4]. Nevertheless, a report of WE in the absence of intractable emesis suggests that other factors may play a role in the development of WE in postoperative LSG patients [5].

We report a case of WE that occurred following LSG and presented with unusual fundus findings.

\section{Case Report}

A 37-year-old woman suffering from morbid obesity without comorbidities underwent LSG and lost $57 \mathrm{lbs}$ ( $25.8 \mathrm{~kg}$ ) over a 2-month period (her body mass index was reduced from 43 to 35). At 3 weeks postoperatively, she presented to the emergency room with epigastric abdominal pain, dysphagia, and elevated serum levels of amylase and lipase that were attributed to a small pseudocyst demonstrated by an abdominal computed tomography scan. Under conservative treatment her symptoms gradually subsided, and she was discharged in a satisfactory condition. However, the patient did not maintain a balanced nutrition and was not compliant with the vitamin supplementation that was recommended after surgery. She then returned at 10 weeks postoperatively with poor oral intake, confusion, postural imbalance (requiring a wheelchair for ambulation), and visual impairment.

There was no history of any systemic disorders, including hypertension and diabetes, as well as any ophthalmic disorders. She denied fever, headaches, abdominal pain, nausea, vomiting, or heartburn. Alcohol use was ruled out. On ophthalmologic examination, extraocular movements were not limited, but a bilateral horizontal nystagmus was present. Visual acuity was 20/20 in both eyes, and anterior segments were normal. Pupil function tests were normal, and no relative afferent pupillary defect was present. Dilated exam showed bilateral optic disc swelling with an adjacent preretinal hemorrhage in the left eye (Fig. 1). Workup included normal laboratory tests except for low thiamine levels $(13.9 \mathrm{ng} / \mathrm{mL}$, normal range 32-95 ng/mL). These findings supported the diagnosis of $\mathrm{WE}$, and she began intravenous thiamine replacement therapy. The nystagmus had regressed a few days after the initiation of thiamine supplementation, and the fundus findings had resolved completely by 3 months. 


\section{Case Reports in Ophthalmology}

\section{Discussion}

Thiamine is absorbed mostly in the jejunum and ileum via both active transport and passive diffusion and has a biologic half-life of approximately 10-20 days. Due to a limited tissue storage, continuous intake is required for maintenance of its intracellular reserve [6].

Although WE represents an acute neurological disorder that manifests with the classic triad of ophthalmoplegia and nystagmus, confusion, and motor ataxia, only $16 \%$ of the patients will exhibit all 3 features at presentation, and low thiamine levels may confirm the diagnosis only later [1].

Due to the profound cognitive consequences of the lack of immediate treatment, thiamine replacement should be started immediately. Empirical treatment with $500 \mathrm{mg}$ of thiamine hydrochloride infused over $30 \mathrm{~min}, 3$ times a day for 2-3 days, and an additional 250 $\mathrm{mg}$ of thiamine given intravenously or intramuscularly daily for 3-5 days, or until resolution of symptoms, were shown to be effective [7,8].

WE is often associated with alcoholism but also noted to have an increased prevalence among undernourished patients. The characteristic presentation of thiamine deficiency following bariatric surgery may develop 4-12 weeks after the procedure [3]. Whereas this syndrome is well known for its classic triad of ophthalmoplegia, confusion, and ataxia, patients may also develop much less recognized neuro-ophthalmic symptoms, such as visual disturbances, diplopia, and nystagmus, as noted in our patient. Fundus signs, such as retinal and preretinal hemorrhages, optic disc swelling, and peripapillary telangiectasia, were only rarely previously documented in WE [9-11], and it has been suggested that they are due to impaired mitochondrial functions in retinal ganglion cells and capillaries or necrosis of optic nerve cells and myelinated structures in the optic nerve resulting in edema [9].

In conclusion, visual symptoms and neuro-ophthalmic findings in patients who underwent bariatric surgery may be an early sign, and a herald clinical finding, of a serious illness, such as WE, that may be reversed by immediate treatment. Fundoscopy should be part of the routine examination of patients with WE as well as of those with clinical and historical risk factors, such as bariatric surgery. This case report adds to the scant literature on the ocular findings in WE and also serves to raise the awareness of the potential complication of vitamin deficiencies following bariatric surgery and the possibility of ocular involvement associated with them.

\section{Statement of Ethics}

The described patient has given informed consent to the publication of this report.

\section{Disclosure Statement}

None of the authors have any proprietary interest in the publication of this work.

\section{References}

Sechi G, Serra A: Wernicke's encephalopathy: new clinical settings and recent advances in diagnosis and management. Lancet Neurol 2007;6:442-455. 


\section{Case Reports in \\ Ophthalmology}

\begin{tabular}{l|l}
\hline DOI: 10.1159/000478924 & C 2017 The Author(s). Published by S. Karger AG, Basel \\
\hline
\end{tabular}
www.karger.com/cop

Serlin and Moisseiev: Fundus Findings in Wernicke Encephalopathy

-2 Stroh C, Meyer F, Manger T: Beriberi, a severe complication after metabolic surgery - review of the literature. Obes Facts 2014;7:246-252.

-3 Singh S, Kumar A: Wernicke encephalopathy after obesity surgery: a systematic review. Neurology 2007;68:807-811.

4 Milone M, Di Minno MN, Lupoli R, Maietta P, Bianco P, Pisapia A, Gaudioso D, Taffuri C, Milone F, Musella M: Wernicke encephalopathy in subjects undergoing restrictive weight loss surgery: a systematic review of literature data. Eur Eat Disord Rev 2014;22:223-229.

-5 Saab R, El Khoury M, Farhat S: Wernicke’s encephalopathy three weeks after sleeve gastrectomy. Surg Obes Relat Dis 2014;10:992-994.

6 Institute of Medicine (US) Standing Committee on the Scientific Evaluation of Dietary Reference Intakes and its Panel on Folate, Other B Vitamins, and Choline: Dietary Reference Intakes for Thiamin, Riboflavin, Niacin, Vitamin B6, Folate, Vitamin B12, Pantothenic Acid, Biotin, and Choline. Washington, DC, National Academies Press (US), 1998.

7 Hope LC, Cook CCH, Thomson AD: A survey of the current clinical practice of psychiatrists and accident and emergency specialists in the United Kingdom concerning vitamin supplementation for chronic alcohol misusers. Alcohol Alcohol 1999;34:862-867.

8 Cook CC: Prevention and treatment of Wernicke-Korsakoff syndrome. Alcohol Alcohol Suppl 2000;35:19-20.

-9 Bohnsack BL, Patel SS: Peripapillary nerve fiber layer thickening, telangiectasia, and retinal hemorrhages in Wernicke encephalopathy. J Neuroophthalmol 2010;30:54-58.

$\checkmark 10$ Lawton AW, Frisard NE: Visual loss, retinal hemorrhages, and optic disc edema resulting from thiamine deficiency following bariatric surgery complicated by prolonged vomiting. Ochsner J 2017;17:112-114

11 Guler A, Alpaydin S, Sirin H, Calli C, Celebisoy N: A non-alcoholic Wernicke's encephalopathy case with atypical MRI findings: clinic versus radiology. Neuroradiol J 2015;28:474-477.
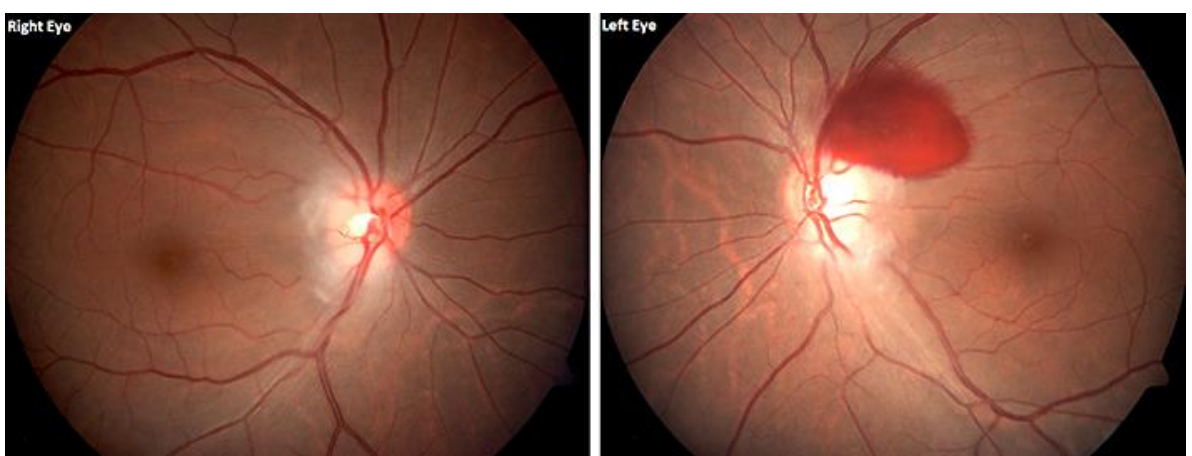

Fig. 1. Fundus photographs of a patient with Wernicke encephalopathy. In the right eye, there was optic disc edema, and in the left eye, optic disc edema was accompanied by an adjacent superior preretinal hemorrhage. 